Inaugural International Association of Student Surgical Societies Symposium

To the Editor: A noteworthy event for global undergraduate surgical education took place when the University of Cape Town Student Surgical Society successfully hosted the inaugural International Association of Student Surgical Societies (IASSS) Symposium.

The IASSS is a recently established global surgical society with the objectives of creating an international movement to represent the needs of surgical societies, developing partnerships between these societies across the globe, and facilitating surgical open education, surgical electives and undergraduate research. While students run the society, the IASSS is fortunate to be able to call on the mentorship of patrons Profs Del Kahn (UCT) and Georges Azzie (University of Toronto).

The symposium was held at UCT on 7 - 10 July 2014, and had an exceptional turnout of 115 undergraduate delegates from five continents and 15 countries. The theme of the symposium was 'Pioneering in surgery', and delegates were treated to a programme filled with engaging talks by world-renowned speakers, practical workshops, a high-quality research competition and an intriguing debate on surgical training in developing v. developed countries. Some highlights of the programme included talks on 'The scope of ENT surgery' (which included a live endoscopic cadaver dissection) by Dr Darlene Lubbe and 'The brains for neurosurgery' by Prof. Anathony Figaji, and a workshop on FATE (focused assessment with trans-thoracic echocardiography) and eFAST (extended focused assessment with sonography for trauma). The symposium afforded the perfect forum for networking with tomorrow's leaders in surgery, fostering collaboration between societies and sharing of ideas. This was illustrated by a student-led transcontinental multicentre research study that is currently in process.

Among many guests, the symposium hosted Prof. Sats Pillay, Treasurer of the International Surgical Society (ISS/SIC), which has endorsed the IASSS as being 'in line with the ISS/SIC endeavours'.

With an official IASSS surgical journal, the Journal of Surgical Sciences, established and the next symposium already being planned, the future looks bright for the IASSS and student surgical education.

\title{
Nicholas Rich
}

Medical Student, University of Cape Town, and Treasurer, IASSS and

UCT Surgical Society, 2014

10nicholas.rich@gmail.com 